\title{
Pedestrian safety at urban crossings in Estonia
}

\author{
D. Antov ${ }^{1,2}$, T. Rõivas ${ }^{1}$, H. Rõuk ${ }^{2}$ \& Ü. Mander ${ }^{1}$ \\ ${ }^{1}$ Institute of Geography, University of Tartu, Estonia \\ ${ }^{2}$ Stratum Ltd, Tallinn, Estonia
}

\begin{abstract}
Road accidents and their consequences are a significant social problem. This topic can also be considered to be one of the indicators of the sustainable development of urban systems. More than 10,000 pedestrians and cyclists are killed every year in EU countries, representing more than $20 \%$ of all road deaths. The small proportion of pedestrian and cyclist casualties that occur in rural areas are relatively severe and should not be forgotten, but this review is concerned with the majority, which occur in urban areas.

Pedestrian safety is also one of the most serious problems in Estonian traffic, especially in urban areas. If one compares Estonia's figures with those of neighbouring Finland, pedestrian road traffic risk in Estonia is 2-4 times higher, for some reason. It is important to note that a number of road accidents occur at or near non-signalized pedestrian crossings.

It is a well documented fact that the road traffic risk of pedestrian fatality or injury is related to drivers' behavioural aspects, such as speed choice when approaching the crossing, and a driver's willingness to yield to pedestrians at non-signalized crossings.

The paper gives an overview of the survey of drivers' behaviour, in which drivers' attitudes to giving way to pedestrians were studied. Vehicle speed in the vicinity of zebra crossings was measured using the in-flow moving method and GPS receivers installed in vehicles.

Keywords: drivers' behaviour, pedestrian crossing, road safety, speed.
\end{abstract}

\section{Introduction}

Road accidents and their consequences are a significant social problem. At the same time, this topic can be considered to be one of the indicators of the sustainable development of urban systems. More than 10,000 pedestrians and 
cyclists are killed every year in EU countries, representing more than $20 \%$ of all road deaths. The small proportion of pedestrian and cyclist casualties that occur in rural areas are relatively severe and should not be forgotten, but this review is concerned with the majority, which occur in urban areas.

Pedestrian safety is also one of the most serious problems in Estonian traffic, especially in urban areas. If one compares Estonia's figures with those of neighbouring Finland, pedestrian road traffic risk in Estonia is 2-4 times higher, for some reason. It is important to note that a number of road accidents occur at or near non-signalized pedestrian crossings.

It is a well documented fact that the road traffic risk of pedestrian fatality or injury is related to drivers' behavioural aspects, such as choice of speed when approaching a crossing and also the driver's willingness to yield to pedestrians at non-signalized crossings.

The main objectives of this study are: (1) to analyse accidents at pedestrian crossings in Estonian cities, (2) to give an overview of drivers' speed behaviour at pedestrian crossings, (3) to make recommendations concerning measures that should be introduced when planning safety measures for pedestrian crossings in Estonia.

\section{Comparison of the situation in Estonia and the EU-15 countries}

After the re-establishment of Estonian independence, the level of motorization has risen rapidly (from 211 to 387 automobiles per 1000 inhabitants). At the same time, the differences in the road safety situation between the old and new EU members remain great.

Even if Estonia has achieved visible progress in road safety, the country remains among those with the poorest road safety statistics in the EU. One of the most alarming issues in road safety in Estonia is pedestrian safety

The per capita risk of pedestrian death in the EU-15 countries in 1996 is shown in Table 1. These figures represent pedestrians' per capita risk of the activity. In order to obtain a better understanding of the risk to pedestrians, each country needs to collect information on the amount of walking.

During the period from 1998-2002, the police reported 1142 fatalities on Estonian roads. Of these, pedestrians accounted for 361 fatalities. Thus every third person killed on the road is a pedestrian. In Estonia, the police only record pedestrian accidents in which at least one vehicle was also involved. The police do not record single accidents, such as falls.

Thus taking into account the risk data of the old EU countries in 1996 and comparing the pedestrian risk indicators with Estonian ones, we can determine that the pedestrian fatality risk is, for some reason, on average three times higher than in the old EU, and even 7 - 8 times higher than in the countries with the best safety characteristics, such as the Netherlands and Sweden. The share of pedestrian accidents is extremely high at urban crossings, contributing more than 90 percent of casualty accidents. 
Table 1: Per capita risk of death of pedestrians in EU-15 countries in 1996 [1] and in Estonia (1998-2003) [2].

\begin{tabular}{|l|c|c|c|c|c|c|}
\hline Country & $\begin{array}{c}\text { Popu- } \\
\text { lation, } \\
\text { mill. }\end{array}$ & \multicolumn{2}{|c|}{$\begin{array}{c}\text { Number of } \\
\text { fatalities }\end{array}$} & \multicolumn{2}{|c|}{$\begin{array}{c}\text { Fatalities per million } \\
\text { population }\end{array}$} & $\begin{array}{c}\text { Percentage } \\
\text { of } \\
\text { fatalities } \\
\text { where } \\
\text { pedestrians } \\
\text { involved }\end{array}$ \\
\cline { 3 - 7 } & & $\begin{array}{c}\text { Total } \\
\text { rians }\end{array}$ & Total & Pedestrians & & 15 \\
\hline BEL & 10.18 & 1336 & 155 & 131 & 15 & 11 \\
\hline GER & 81.90 & 8758 & 1178 & 107 & 14 & 14 \\
\hline DAN & 5.29 & 514 & 68 & 97 & 13 & 13 \\
\hline ESP & 39.68 & 5483 & 960 & 138 & 24 & 18 \\
\hline FRA & 58.21 & 8541 & 1043 & 147 & 18 & 12 \\
\hline FIN & 5.13 & 404 & 70 & 79 & 14 & 17 \\
\hline GRE & 10.48 & 2063 & 469 & 197 & 45 & 23 \\
\hline ITA & 57.25 & 6688 & 987 & 117 & 17 & 15 \\
\hline IRL & 3.58 & 453 & 113 & 127 & 32 & 25 \\
\hline NED & 15.60 & 1180 & 109 & 76 & 7 & 9 \\
\hline POR & 9.82 & 2730 & 624 & 278 & 64 & 23 \\
\hline SWE & 8.82 & 537 & 74 & 61 & 8 & 14 \\
\hline UK & 58.29 & 3740 & 1039 & 64 & 18 & 28 \\
\hline EST* & 1.35 & 228 & 72 & 169 & 53 & 32 \\
\hline
\end{tabular}

* Estonian data - annual average from 1998-2003 [1,2].

The Estonian national Road Safety Programme was passed in the Estonian Parliament in 1988. This plan contained a clear goal: the number of fatalities should be reduced by at least $50 \%$ by the end of 2015 , and thus the number of fatalities should not exceed 100 in 2015. The goal is absolute, i.e., it must be attained even in the event of changes in traffic conditions, such as increasing motorization and traffic. It is also a quantitative goal, which means, for instance, that no attempt will be made to attain it in certain groups of road users in preference to other groups.

\section{Pedestrian risk and motor vehicle speed}

The choice of exposure is crucial to any comparison of own risk across different modes of transport. The reason for this is that the speeds and durations of the individual trips differ between the various modes of transport.

Figure 1 illustrates how the fatality and injury risk of pedestrians depends on the motor vehicle's speed in a collision situation. It could be deduced that pedestrian fatality and injury risks are highly dependent on collision speed. Thus the probability of staying alive in a collision is about six times higher when collision speed is $30 \mathrm{~km} / \mathrm{h}$ instead of $50 \mathrm{~km} / \mathrm{h}$. In the case of a $70 \mathrm{~km} / \mathrm{h}$ collision 
speed, the probability of being killed in an accident is almost $95 \%$, but only $15 \%$ at a collision speed of $40 \mathrm{~km} / \mathrm{h}$. All of these speeds, however, are common at zebra crossings, since speed limits, and the actual speeds of individual motor vehicles, could be much higher that that.

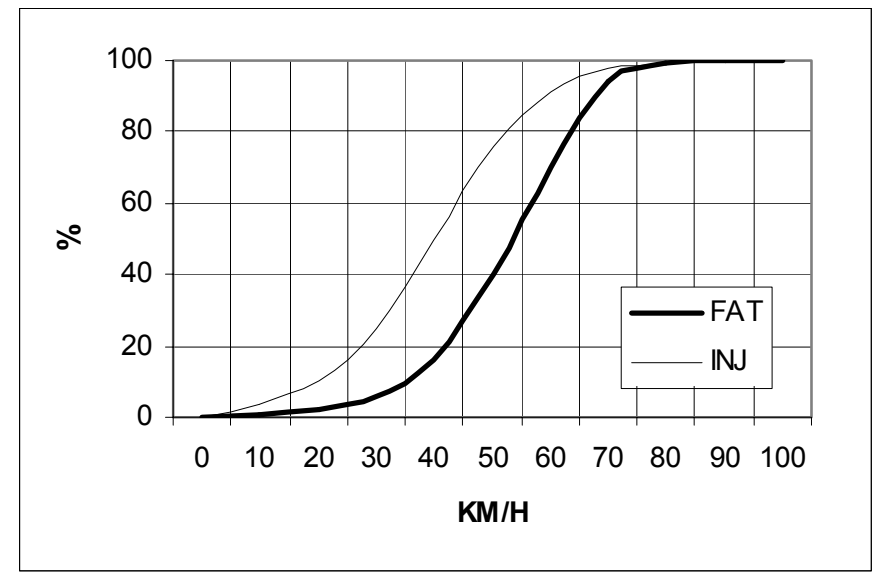

Figure 1: Probability (\%) of pedestrian fatality (FAT) and injury (INJ) depending on motor vehicle's collision speed [3].

\section{International risk evaluation of zebra crossings}

According to the Estonian Road Traffic Act, a zebra crossing is a part of the road that is provided for pedestrians to cross the carriageway and is specially marked. If there is a zebra crossing in the vicinity, pedestrians must use it when crossing carriageways. Drivers approaching a non-signalised zebra crossing must adapt their speed so that they can stop in order to give way to pedestrians who are just entering the crossing. If necessary, drivers must stop in order to allow pedestrians to pass. Drivers approaching a zebra crossing must not overtake or pass another vehicle if that vehicle obstructs full view of the crossing.

The risk to pedestrians crossing roads at various points in traffic systems has been studied in a series of studies from England [4, 5] and Sweden [6]. The same method was used in all of these studies. The number of accidents in which crossing pedestrians was involved was compared to the number of pedestrians crossing within a fixed period (12 min. counts were used outside the rush hour). One study found that the risk involved in crossing road sections at up to 45.7 metres from a zebra crossing including the crossing itself was 30\% higher than that at over 45.7 metres from a zebra crossing, whereas three other studies found that the risk was up to $50 \%$ lower. Three studies found that the risk involved in crossing roads at or near non-signalised junctions, at distances of up to 18.3 metres from the junctions and up to 45.7 metres from a zebra crossing was up to $127 \%$ higher in comparison to that at non-signalised junctions lacking zebra crossings, although two other studies found that the risk was up to $35 \%$ lower. 
The effects of other circumstances, such as central islands, road lighting and road width were not eliminated in the studies.

In New Zealand, the risk to crossing pedestrians has been found to be $15 \%$ lower at non-signalised zebra crossings, in comparison to crossing roads at any other point. Pedestrian exposure was estimated through interviews. No allowance was made for possible differences in the occurrence of other measures, quantities of car traffic and speed of car traffic [7].

Draskóczy and Hydén [8] point out that the give-way rules possibly influenced the effect of the pedestrian crossings. Even though most studies indicate a negative safety effect of pedestrian crossings, there are exceptions, e.g. from England and Norway. England and Norway have clear give-way rules which require vehicles to give way to pedestrians, whereas other countries, such as Sweden, had no such rules. Draskóczy and Hydén thus suggest introducing clear give-way rules in the Swedish Road Traffic Act, so that zebra crossings should reduce the number of accidents in which crossing pedestrians are involved.

Swiss traffic regulations were amended in 1994, so that vehicles must give way when the behaviour of a pedestrian clearly indicates that he or she intends to use a zebra crossing. Earlier, pedestrians needed to signal to drivers that they wished to cross the road. It was possible to conclude on the basis of behaviour studies that the average number of vehicles that drove past before waiting pedestrians crossed the road dropped from 2.6 in the before period to 1.5 in the after period. The proportion of motorists who stopped/braked and allowed pedestrians to cross the road increased from $12.5 \%$ in the before period to $31.6 \%$ in the after period one year after amendment of the give-way rules [9].

Based on the literature, Varhelyi [10] writes the following about nonsignalised zebra crossings:

- The presence of pedestrians at zebra crossings has little or no influence on the speed of approaching vehicles

- Between 4 and 30\% of vehicle drivers give way to pedestrians at zebra crossings.

- Drivers are more willing to slow down or stop for crossing pedestrians when the approach speed of the vehicle is low.

A Swedish interview survey showed that crossing pedestrians feel safer at zebra crossings than they are away from them [11]. This should possibly be considered in the context that pedestrians walk about $10 \%$ faster when crossing a road away from a zebra crossing than they do at such crossings [12].

\section{Materials and methods}

\subsection{Motor vehicle user speed at the vicinity of zebra crossings}

The former surveys contain indications that, when installing zebra crossings and road lighting, the safety effects obtained for pedestrians depend on the speed 
level of vehicular traffic and the quantity of traffic. It is thus important to determine the speed values at crossings, but especially to determine whether the crossing itself has any influence on drivers' speed choice when approaching the crossing.

It should be highlighted that the technical data were obtained from a special survey that aimed to analyse data about real speeds and delays when moving in the urban street network. The car, which was equipped with a GPS receiver, video recorder and data storage devices, used the in-flow driving method at previously chosen routes in Tallinn. The car's speed and location was fixed every second while in motion. Later the location of non-signalized crossings on the chosen routes was assigned, and thus it was possible to survey actual driving speeds at the vicinity of zebra crossings. It is important to understand that situations involving waiting for crossing pedestrians (contacts) were eliminated from the survey this time, as we were interested only on the influence of empty crossings on speed choice.

Each route was driven at least six times, mainly at off-peak hours, where speed choice was relatively free. In eliminating situations involving contact with pedestrians, the total number of measured situations was 120 at 29 crossings, at 24 of which the speed limit was $50 \mathrm{kph}$, and at 5 crossings it was $70 \mathrm{~km} / \mathrm{h}$. The speed was measured at 4 locations in the vicinity of the crossing - at $100 \mathrm{~m}$ (coded here as -100) and $50 \mathrm{~m}$ before the crossing (coded as -50), at the crossing (coded as 0 ) and at $50 \mathrm{~m}$ after the crossing (coded as +50$)$.

\section{Main results of the study}

The average speeds at crossings are quite high. In almost $60 \%$ of runs the measured speed was greater than the speed limit. The measured speed was less than $40 \mathrm{kph}$ at only $12 \%$ of runs. The situation was especially dangerous at crossings where the speed limit is $70 \mathrm{~km} / \mathrm{h}$. The lowest measured speeds were between 55 and $60 \mathrm{~km} / \mathrm{h}$. The running speed distribution measured at crossings is presented in Figures 2 and 3.

The change in speed at the vicinity of zebra crossing is minor. It is important to note that in comparing speeds at -100 and 0 , the speed at the crossing was less than that at -100 in only $59 \%$ of cases. The respective data at -50 and 0 represent $57 \%$ of cases. Thus in nearly half of measured cases the speed was not lowered at the crossing in comparison with the speed at 100 and $50 \mathrm{~m}$ from the crossing.

The data obtained from the survey also shows that braking, if ever, starts very near the crossing. After passing, the speed regularly rises again a very short distance after zebra crossings. The typical speed change in the vicinity of crossings is illustrated in Figures 4 and 5.

The main conclusion of the survey is that the existing shape of non-signalized pedestrian crossings does not cause drivers to lower speed to a safe speed, and in the case of collision, the risk of injury or fatality remains very high. The results of this study are in almost full compliance with previous studies by Draskóczy and Hydén [8] and Varhelyi [10]. 


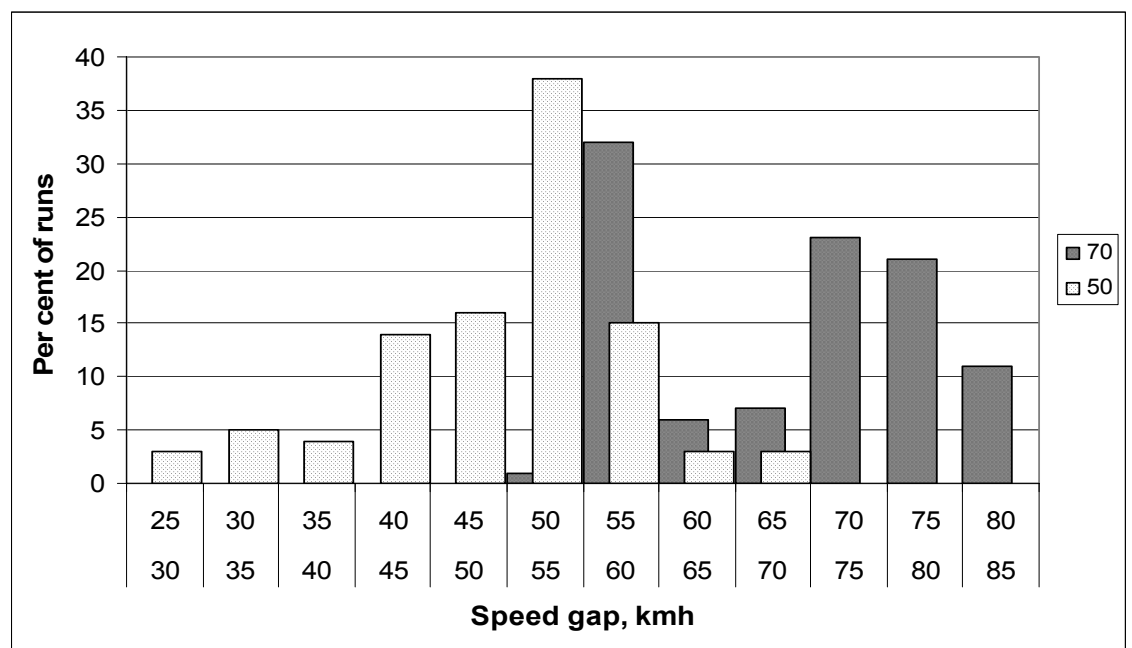

Figure 2: Distribution of running speed at pedestrian crossings at speed limit of 50 and $70 \mathrm{~km} / \mathrm{h}$.

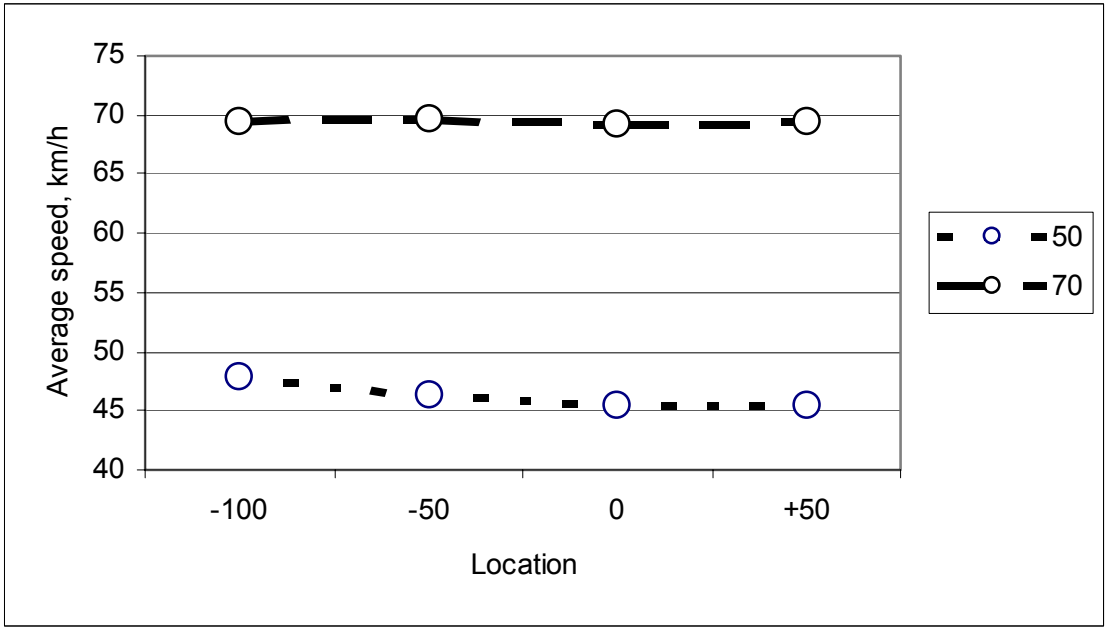

Figure 3: Typical speed behaviour in the vicinity of zebra crossings at different speed limits (50 and $70 \mathrm{~km} / \mathrm{h}$ ).

The situation is especially critical at crossings with a speed limit of $70 \mathrm{~km} / \mathrm{h}$. At these locations the average speed is dangerously high in the whole vicinity of zebra crossing and does not allow for safe braking when the driver notices a pedestrian waiting at the roadside. Thus these sites do not follow the traffic rules of giving way, and should be discarded. This recommendation is an important point to be followed in the new version of urban street design standard. 
804 The Sustainable City IV: Urban Regeneration and Sustainability

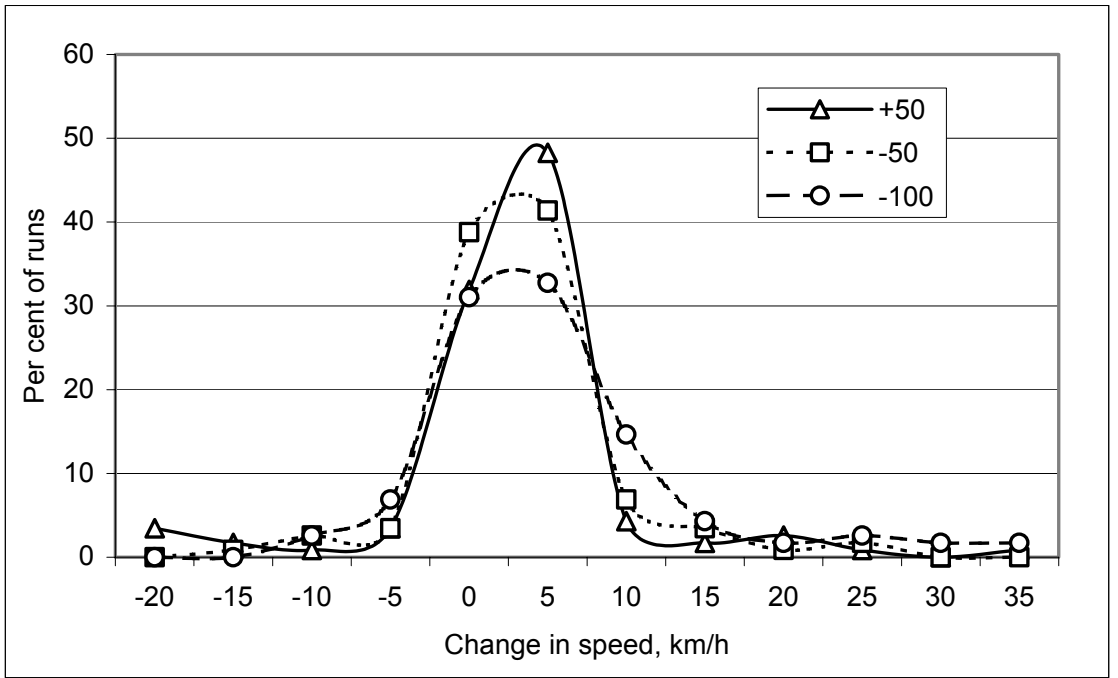

Figure 4: Speed differences comparing running speed at different distances $(+50,-50$, and $-100 \mathrm{~m})$ from pedestrian crossing $(\mathrm{km} / \mathrm{h})$.

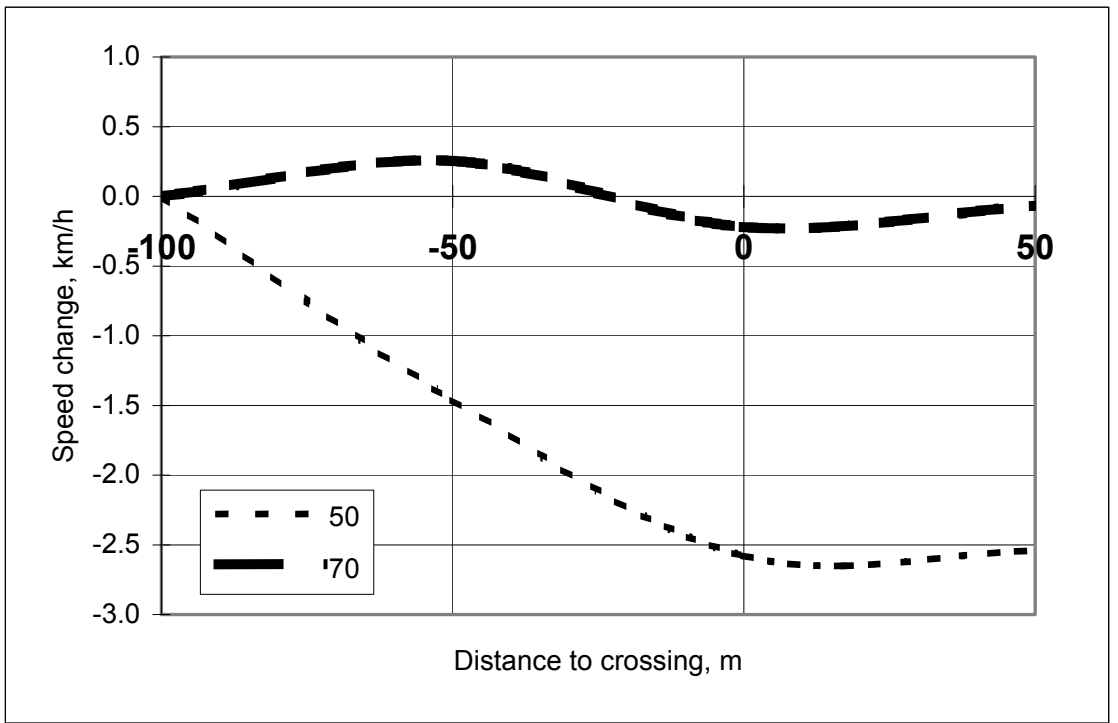

Figure 5: Typical speed curves in the vicinity of pedestrian crossings at two speed limits, 50 and $70 \mathrm{~km} / \mathrm{h}$. 


\section{Conclusions}

This report is based on field surveys and data analyses about pedestrian safety. The key topics are: accident and risk developments for pedestrians, motorists' behavioural aspects at zebra crossings, particularly their obligation to give way, and also speed choice in the vicinity of a zebra crossing, as well as the safety effect for pedestrians of zebra crossing design. The key results are summarized below.

- The pedestrian casualty risk in Estonia is on average approximately $2 \ldots 6$ times higher than in other older EU countries.

- $44 \%$ of pedestrian casualties occurred in urban areas during the period from 1998-2002. Pedestrian accidents are predominant in urban areas.

- Urban non-signalized pedestrian crossings remain one of the risky sites for pedestrians.

- The average speed and speed distribution of motorized vehicles has a major influence on pedestrian safety. There is a clear relationship between the permitted speed and the severity of pedestrian injuries in accidents. The proportion of fatalities among pedestrian casualties increases in step with increasing permitted speed. In other words - speed kills.

- The existing shape of pedestrian crossings does not have a great influence on drivers' speed choice. The average driving speed at pedestrian crossings is high, and this speed is not significantly lowered when approaching the pedestrian crossing.

- An especially bad situation is recognized at pedestrian crossings where the speed limit for motorists is $70 \mathrm{~km} / \mathrm{h}$. The normal rule of giving way to pedestrians does not usually apply here. Drivers regularly ignore give way obligations, do not lower their speed, and in the event pedestrians cross the road, they just have a sufficient gap between motor vehicles.

- There is an urgent need to reconstruct pedestrian crossing in a modern and safe way. Some crossings should be liquidated or replaced by signalized ones, especially where it is impossible to apply safety standards, or it is considered necessary to maintain the higher than usual speed limit.

Altogether, the main task for pedestrian safety is to lower the casualty rate for crossing pedestrians. Most pedestrian accidents occur in urban areas. Elderly pedestrians, intoxicated pedestrians and pedestrians crossing in darkness are also important target groups in implementing measures against fatal accidents. Thus this is greatly needed to introduce new modern standards in pedestrian crossing design, in order to lower speeds and improve driver visibility in the vicinity of pedestrian crossings.

\section{Acknowledgement}

This study was supported by Target Funding Project No. $0182534 \mathrm{~s} 03$ of the Ministry of Education and Science of Estonia. 


\section{References}

[1] IRTAD (International Road Traffic and Accident Database). http://www.bast.de/htdocs/fachthemen/irtad/english/irtadlan.htm)

[2] Statistics of Fatal and Injurious Road Traffic Accidents in Estonia 2004. Estonian Road Administration, 2005.

[3] Nilsson, G., Relationship between speed and safety: Calculation method. The Speed Review: Appendix of Speed Workshop Papers, Federal Office of Road Safety, Report CR127A, Department of Transport and Communications, Canberra, 1993.

[4] Mackie, A.M. \& Older, S.J., Study of pedestrian risk in crossing busy roads in London inner suburbs. Traffic Engineering and Control, vol. 7, pp. 376-380, 1965.

[5] Jacobs, G. \& Wilson, D., A Study of Pedestrian Risk in Crossing Busy Roads in Four Towns. Road Research Laboratory, Report LR 106, Crowthorne, UK, 1967.

[6] Ekman, L. \& Kronborg, P. Traffic safety and pedestrians and cyclists at signal controlled intersections. Institutet för transportforskning, Stockholm, Sweden, 1995.

[7] Keall, M.D., Pedestrian exposure to risk of road accidents in New Zealand. Accident Analysis and Prevention, vol. 27, no. 5, pp. 729-740. 1995

[8] Draskóczy, M. \& Hydén, C., Pedestrian safety measures - past and future. ICTCT's $7^{\text {th }}$ Workshop on Pedestrians Problems, Prague, Czech Republic, 1994.

[9] Ewert, U., New pedestrian-crossing regulation: Changes in the behavior of pedestrians and car drivers. ICTCT's $8^{\text {th }}$ Workshop on Safety of Urban Transport With Focus on Pedestrian Problems, Paris, France. 1995.

[10] Varhelyi, A., Drivers' speed behavior at a zebra crossing. KFBMeddelande 16. Lunds Tekniska Högskola, Lund, Sweden, 1996.

[11] Pedestrian Safety. Analyses and Safety Measures. Report 148. Danish Road Directorate, 1998.

[12] Dewar, D., Knoblauch, R., Nitzburg, M., Pietrucha, M., Templer, J., Older pedestrian characteristics for use in highway design. Federal Highway Administration Report, USA, 1995. 